\title{
Two distinct morphs in the wood ant Formica polyctena in Finland: a result of hybridization?
}

\author{
Jouni Sorvari
}

Sorvari, J. 2006: Two distinct morphs in the wood ant Formica polyctena in Finland: a result of hybridization? — Entomol. Fennica 17: 1-7.

Wide overlaps in morphological characters among species in mound building wood ants of the Formica rufa-group have been a long-standing problem. Previous studies suggest that Formica polyctena samples from Finland may represent two different types based on queen morphology. However, worker caste has not been studied completely. I found that hairiness of workers from different colonies was bimodally distributed. Morphs (based on bimodality) differed in the abundance of erect hairs on eight out of 11 studied body parts. The hairier morph may be result of incomplete reproductive isolation between closely related species.

J. Sorvari, Section of Ecology, Department of Biology, University of Turku, FI20014 Turku,Finland; E-mail: jouni.sorvari@utu.fi

Received 5 October 2004, accepted 24 February 2005

\section{Introduction}

Accurate identification of species in moundbuilding wood ants of the Formica rufa-group has been a long-standing problem. Relative abundance of hairs on different body parts as well as some chitin structures (sculpture and punctures) are used in identification of the wood ants of the European F. rufa-group (e.g., Collingwood 1979, Collingwood \& Agosti 1986). Seifert (1996) also used the length of hairs as an additional identification character. However, species identification is difficult, mostly because those characters overlap widely among species (Collingwood 1979, Douwes 1979, Pamilo et al. 1979, Vepsäläinen \& Pisarski 1981, Collingwood \& Agosti 1986, Czechowski \& Douwes 1996). In particular, making a clear distinction between Formica polyctena Förster and Formica aquilonia Yarrow is difficult in some regions in northern Europe (Rosengren 1977, Collingwood 1979, Pamilo et al. 1979, Vepsäläinen \& Pisarski 1981). There have been few studies on morphological taxon- omy in European F. rufa-group over the last 15 years (e.g., Seifert 1991, Seifert 1992, Czechowski \& Douwes 1996), and more studies are needed to improve identification of species in this group.

Rosengren (1977) found that Finnish F. polyctena might consist of similar forms that differ mostly in the morphology of queens [i.e. reproductive female caste; see also Collingwood (1979) and Collingwood \& Agosti (1986)]. However, a thorough study of workers is still missing. In this study my goal was to determine whether there are two distinguishable morphs within $F$. polyctena workers collected in Finland.

\section{Material and methods}

\subsection{Study species}

The study species $F$. polyctena is polygynous (i.e. multiple queens in same nest) and polydomous (i.e. multiple more or less co-operating nests. It 
belongs to the European mound building Formica rufa-group (Collingwood 1979, Rosengren \& Pamilo 1983, Seifert 1996). The nests of this group are very populous, and Seifert (1996) suggested that over 5 million ants might live in a large nest. The species is the dominant wood ant in large forests in western continental Europe (Collingwood 1979, Czechowski \& Douwes 1996, Seifert 1996) and is locally dominant in Finland (Rosengren \& Pamilo 1983). It inhabits forest edges and interiors (Seifert 1996), and like other wood ants has a strong impact on the composition of the local ant community (Savolainen \& Vepsäläinen 1988, Savolainen \& Vepsäläinen 1989, Savolainen et al. 1989) and arthropod fauna (Adlung 1966, Niemelä et al. 1992, Punttila et al. 2004).

\subsection{Samples and morphological characters}

A total of 259 worker-ants of $F$. polyctena from 12 different nests and 150 workers of $F$. aquilonia from 11 different nests were used in this study. The F. polyctena samples (10-30 workers/nest) were collected from separate places in central and southern Finland in 1999 and 2000 (Table 1). The $F$. aquilonia samples used as a comparison group were collected from separate places in southern, central and northern Finland. Owing to polydomy, neighbouring nests may not be independent from each others because the nests may represent same genetic strain. In addition, worker exchange may be high among nests in polydomous colonies. Using samples from different forests should give independent samples for statistical analyses. The samples were collected randomly in relation to this study (collected for purposes of other studies), and all examined samples were included. Samples of both species were identified using the key of Collingwood (1979). Some of the $F$. polyctena colonies were easily identified as $F$. polyctena, whereas ants in other samples were somewhat hairier than typical $F$. polyctena. Though not in the category of its hairier relatives (F. aquilonia, F. rufa, F. lugubris), these ants could not clearly be distinguished from $F$. aquilonia. However, the main characters used in the key (Collingwood 1979), namely the number of hairs on back of head and hind femur, did not
Table 1. Composition and source of $F$. polyctena samples. Caste symbols are $w$ for worker and $q$ for queen. The colony numbers follow the numbers used in Appendix.

\begin{tabular}{lll}
\hline Colony & $\begin{array}{l}\text { Composition } \\
\text { of sample }\end{array}$ & Source \\
\hline 1 & $30 w w, 3$ 우 & Jyväskylä \\
2 & $30 w w, 1$ + & Jyväskylä \\
3 & $29 w w$ & Hanko peninsula \\
4 & $30 w w$ & Hanko peninsula \\
5 & $30 w w$ & Hanko peninsula \\
6 & $30 w w$ & Hanko peninsula \\
7 & $30 w w$ & Hanko peninsula \\
8 & $10 w w$ & Vaanko peninsula \\
9 & $10 w w$ & Turku \\
10 & $10 w w, 4$ 우 & Hanko peninsula \\
11 & $10 w w$ & Kokemäki \\
12 & $10 w w$ & \\
\hline
\end{tabular}

overlap when colony mean values were used (min. - mean - max.: Back of head: F. aquilonia $8.57-12.09-16.87$, F. polyctena $0.10-1.80-$ 4.17; Femur: F. aquilonia 28.20 - $36.18-42.30$, F. polyctena $9.90-18.44-24.57)$.

The number of hairs from 11 different bodyparts was counted by using Olympus SZ40 stereomicroscope with $40 \times$ magnification. The studied body-parts were gula $(\mathrm{Gu})$, clypeus $(\mathrm{Cl}$; excluding the posterior margin), compound-eye (Ey; randomly chosen right or left compoundeye), back of head $(\mathrm{Hb})$, prosternum (Ps; right or left), pronotum (Pn), mesonotum (Mn), propodeum $(\mathrm{Pp})$, mesopleuron $(\mathrm{Mp}$; right or left), petiolus (Pe; excluding ventral side) and hind femur (Fe; right or left, excluding the margin of joint between femur and tibia). The colony mean values of each body-part were summed to obtain colony hairiness index.

The maximum head width (Hw) was measured to the nearest $0.01 \mathrm{~mm}$ with an ocular measurement scale in stereomicroscope (Olympus SZ40). The head width is used as a standard measure of body size in ants (Deslippe \& Savolainen 1994). The location of maximum head width was normally slightly behind eyes (as in Seifert 1991). The colony means ( \pm S. E.) of the characters are presented in Appendix. Ey, Mp, and $\mathrm{Hw}$ were studied from 10 workers from each sample. Other variables were measured from all workers (10-30) of the sample. 
Mean distance between hairs on the first gastral tergite of eight $F$. polyctena queens from three colonies varying in hairiness of workers was studied. Similarly five queens from two $F$. aquilonia colonies were also studied. All of the studied queens were collected as winged queens from the surface of nest mounds in spring 2000, and the date was recorded. Both species had a tendency that hairs and their punctures were absent or rare in the medial dorsal part of the first gastral tergite (especially in F. polyctena). Therefore, mean distance of three pairs of hairs from well outside the medial area (three from both sides) was measured (to the nearest $0.01 \mathrm{~mm}$ ). Micrographs were taken with a scanning electron microscope (SEM; JEOL JSM-5200), and the distance between hair bases were measured with SemAfore 3.0 Pro software. SEM-micrographs of the dorsum of the first gastral tergite have been used earlier in studies of the systematics of $F$. rufa-group by Collingwood (1979) and Collingwood and Agosti (1986).

\subsection{Statistical analyses}

The character differences between groups were studied by using mixed-model ANOVA's with restricted maximum likelihood (REML) method and Satterthwaite approximation for degrees of freedom. When the individual worker data were used, the hierarchical structure of the data (individual worker - nest - group) was controlled by using the nest of origin as a random factor (nested within group). The distributions of head widths were compared with two-sample KolmogorovSmirnov tests. In addition, correlation of hairiness with longitude and latitude was studied, as was the correlation of hairiness of studied body parts with head width. Mixed-model ANOVAs were performed with SAS 8.2 software, whereas the rest of the analyses were performed with SPSS 11.5 statistical software.

\section{Results}

The colony-mean totals of hairs on the body-parts studied ranged from 39.8 to 84.8 among colonies of $F$. polyctena, and the grand colony-mean was

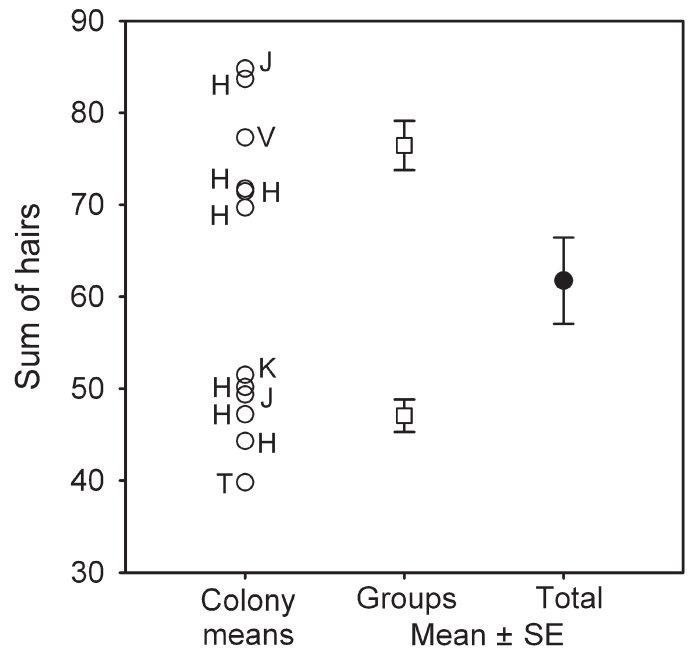

Fig. 1. Number of hairs on worker ants from 12 studied $F$. polyctena colonies. Open circles on the left are colony means of hair counts and capital letters indicates geographical origin of samples ( $\mathrm{J}=$ Jyväskylä, $\mathrm{H}=$ Hanko peninsula, $\mathrm{V}=$ Vaasa, $\mathrm{K}=$ Kokemäki, $\mathrm{T}=$ Turku). Means ( \pm S. E.) of the groups (open squares with error bars) and mean of all colonies (filled circle with error bars) are shown.

61.75 ( \pm 4.7 S. E.) hairs. The colony-mean values, however, were bimodally distributed around the grand colony-mean (Fig. 1). The data were divided into two groups, those being less hairy and those being hairier than the grand colony-mean (hereafter referred to as the less-hairy and hairy morphs). The morphs differed statistically in total hair sums of the examined body parts [means for hairy morph $76.44( \pm 2.7 \mathrm{~S}$. E.) and for less-hairy morph $47.05 \quad( \pm 1.8 \quad$ S. E.); mixed-model ANOVA; $F_{1,10}=83.40, p<0.0001$ ] (Fig. 1). In addition, both morphs differed significantly from $F$. aquilonia [F. aquilonia mean 120.54 ( \pm 6.0 S. E.); mixed-model ANOVA; hairy morph: $F_{1,15}=$ $27.39, p<0.0001$; less-hairy morph: $F_{1,15}=78.32$, $p<0.0001]$.

Difference of each character between $F$. polyctena morphs was analysed using individual worker data and mixed-model ANOVA (colony of origin nested within morph). Among the studied characters $\mathrm{Gu}, \mathrm{Cl}, \mathrm{Hb}, \mathrm{Ps}, \mathrm{Pn}, \mathrm{Mn}, \mathrm{Pp}$ and Fe differed, whereas Hw, Ey, Mp and Pe did not differ between the morphs (Table 2).

Correlations between head width and the hairiness of different body parts were made using 
Table 2. Mixed-model ANOVAs for the number of hairs and head widths $(\mathrm{mm})$ between hairier and less-hairy morphs of $F$. polyctena. The model-based least-square means $( \pm S$. E.) for both groups are given. The unit is number of hairs, except for head width, which is in millimetres. Denominator d. f. (ddf) is shown (nominator d. f. is always 1 in the model). Correlation between each morphological variables and head width is also presented (Spearman $r_{s}$ ).

\begin{tabular}{lrrrrrr}
\hline Morph. character & Hairy & Less hairy & ddf & $F$ & \multicolumn{1}{c}{$p$} & \multicolumn{1}{c}{$r_{s}$} \\
\hline Gula & $5.24 \pm 0.49$ & $2.48 \pm 0.46$ & 12.5 & 16.92 & $<0.0001$ & -0.07 \\
Clypeus & $4.01 \pm 0.35$ & $2.68 \pm 0.32$ & 10.7 & 7.64 & 0.019 & 0.23 \\
Eye & $6.55 \pm 0.91$ & $5.16 \pm 0.79$ & 12.0 & 1.32 & 0.27 & 0.05 \\
Back of head & $3.26 \pm 0.28$ & $0.43 \pm 0.31$ & 7.26 & 45.96 & $<0.0001$ & -0.18 \\
Prosternum & $5.21 \pm 0.67$ & $2.98 \pm 0.61$ & 12.7 & 6.12 & 0.028 & 0.03 \\
Pronotum & $6.43 \pm 0.78$ & $1.95 \pm 0.76$ & 13.1 & 16.61 & $<0.0001$ & $<-0.01$ \\
Mesonotum & $6.14 \pm 0.68$ & $2.82 \pm 0.62$ & 12.0 & 13.05 & 0.0036 & -0.01 \\
Mesopleuron & $6.48 \pm 0.71$ & $5.03 \pm 0.62$ & 12.0 & 2.39 & 0.14 & 0.22 \\
Propodeum & $6.06 \pm 0.59$ & $2.12 \pm 0.57$ & 11.3 & 23.29 & 0.0005 & -0.07 \\
Petiolus & $5.31 \pm 0.58$ & $4.23 \pm 0.54$ & 11.4 & 1.90 & 0.19 & -0.02 \\
Hind femur & $21.54 \pm 1.56$ & $14.14 \pm 1.42$ & 11.1 & 12.31 & 0.0048 & -0.11 \\
Head width & $1.64 \pm 0.05$ & $1.62 \pm 0.04$ & 12 & 0.03 & 0.86 & 1.00 \\
\hline
\end{tabular}

those ants whose head width was measured at the same time as hairs were counted (leaving out 1 nest from Jyväskylä and 5 nests from Hankoniemi). This reduced the data to 60 workers $(20$ from hairy morph and 40 from less-hairy morph), but still gave information for an association between the body size and the hairiness. The hairiness of different body parts was not correlated with head width (in all cases $p>0.05$; Table 2).

The distribution of head widths was similar between the morphs (Two-sample Kolmogorov-

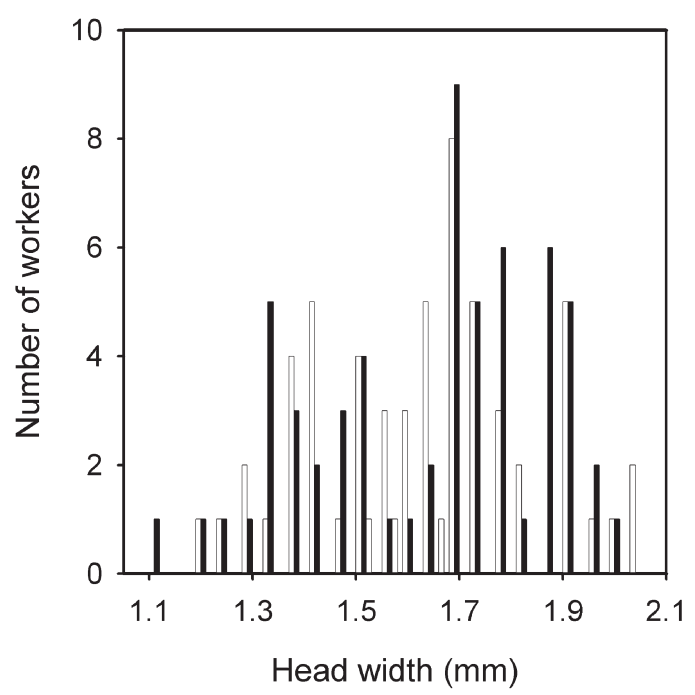

Fig. 2. The head width $(\mathrm{mm})$ distribution of less-hairy (white bars) and hairy types (black bars).
Smirnov test; $Z=0.73$, two-tailed $p=0.66$; Fig. 2 ). Head width was measured from 10 workers per colony, and the both morphs were equally represented (60 workers/morph).

The sum of hairs did not correlate with latitude or longitude (Spearman $r_{s}=0.180, n=12$, two-tailed $p=0.46$; Spearman $r_{s}=0.113, n=12$, two-tailed $p=0.68$; respectively).

The distance between bases of hairs on the first gastral tergite in queens from a colony of hairy morph with the mean 39.63 ( $\pm 9.43 \mathrm{~S}$. E.) $\mathrm{mm}$ was close to intermediate between those of less-hairy morph and F. aquilonia [59.32 ( \pm 3.82 S. E.) mm, 24.72 ( \pm 1.07 S. E.) mm; Fig. 3]. The number of studied queens was low, and thus differences between both of the morphs and species could not be analysed statistically. The colonymean distance between hairs on the first gastral tergite associated significantly negatively with the beginning of the mating flight period, defined as first occurrence of winged queens on the surface of nest mounds (mixed-model ANOVA; $F_{1,4.52}=7.58, p=0.045$; Fig. 3).

\section{Discussion}

On the basis of statistical analyses there are two distinct morphs in Finnish $F$. polyctena, lesshairy and more hairy types. The hairiness of different body-parts did not correlate with the size of 


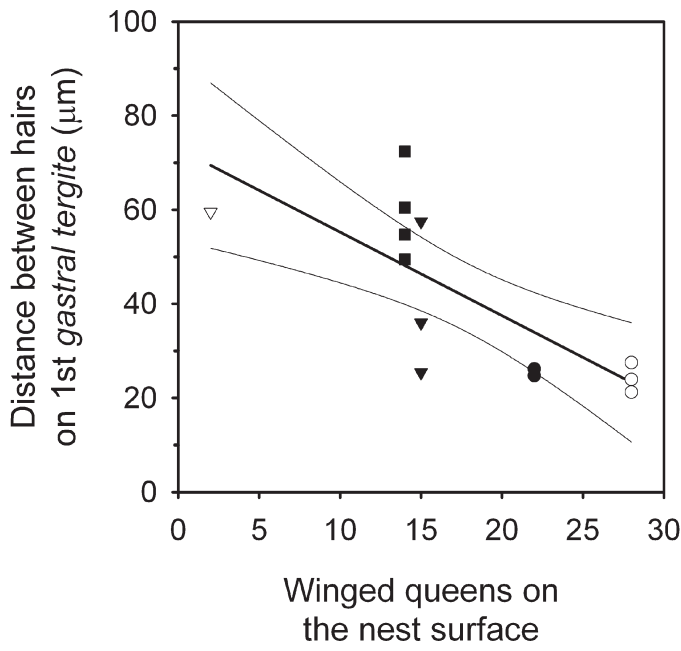

Fig. 3. Mean distance between hairs on queen's first gastral tergite in relation to the beginning of mating period as measured by occurrence of winged sexual offspring on the surface of nest mound ( $0=$ April 30$)$. Open and filled circles are $F$. aquilonia queens from Jyväskylä (central Finland); filled triangles are queens of the hairy morph (colony 1 ); and open triangle (colony 2 ) and filled squares (colony 10) are queens of the less-hairy morph.

ant. The morphs were similar in size, and also the distributions of the sizes were similar. Therefore the difference in hairiness was not a size-related artefact. The absence of correlation between hairiness and both latitude and longitude indicates that hairiness of workers was not due to geographic variation or ecotypes within species, at least not on the scale of the study.

The data strongly suggest that incomplete reproductive isolation is behind the morphs. It has been suggested that taxonomical problems in $F$. rufa-group are severe because of relatively recent speciation (Pamilo et al. 1979, Vepsäläinen \& Pisarski 1981, Collingwood \& Agosti 1986). Goropashnaya et al. (2004) found molecular information on recent speciation in this species group. The members of the species group have mating periods during the spring and the summer with partial overlap among species (Seifert 1996), and thus, interbreeding is theoretically possible.

$F$. polyctena and $F$. aquilonia live sympatrically in southern Finland, but not in northern Finland, where $F$. polyctena seems to be absent
(Collingwood 1979). F. polyctena colonies that were used in this study were sympatric with $F$. aquilonia, although inhabiting different forest patches. It is tempting to think that the reproductive isolation between $F$. polyctena and ecologically similar F. aquilonia is not complete, which could cause variation in hairiness within species, $F$. polyctena in this case. The mating period of the hairy type queens were close to the mating period of $F$. aquilonia, which might increase the probability of interbreeding between species. However, even if the mating periods overlap, species may be reproductively isolated because of different mating behaviour or different dispersal behaviour during mating period [for example flight behaviour of queens; see Rosengren et al. (1993)].

Unusually hairy $F$. polyctena samples have been reported earlier from continental Europe and were suggested to be hybrids of $F$. polyctena and F. rufa (Seifert 1991, Seifert 1996, Czechowski \& Douwes 1996). According to Seifert (1996), the punctures and hairs on dorsal part of the first gastral tergite of queens of $F$. polyctena, F. rufa and their hybrids are widely distributed. In this study, however, the punctures and hairs on dorsal part of the first gastral tergite in queens of the hairy morph had more closely set hairs than in queens of less-hairy morph. Therefore, they probably do not represent hybrids of $F$. rufa and $F$. polyctena, and are more likely hybrids of $F$. polyctena and F. aquilonia, if any. At least in laboratory conditions $F$. polyctena and $F$. aquilonia can produce viable $\mathrm{F}_{1}$ hybrid generation ( $\mathrm{J}$. Sorvari unpubl.).

It is quite likely that the hairy morph of this study is the same as Rosengren's (1977) atypical form of F. polyctena, which is later called Formica 'grankullensis' without assessment of taxonomical rank (Collingwood \& Agosti 1986, Rosengren et al. 1987). Collingwood and Agosti (1986) proposed that the $F$. rufa-group consists of F. rufa, F. lugubris, F. pratensis and F. aquilonia complexes. They suggested that $F$. 'grankullensis' belongs to the $F$. aquilonia complex instead of $F$. rufa complex (where F. polyctena was included), because its chitin structure resembles more $F$. aquilonia than $F$. polyctena. They also proposed that $F$. 'grankullensis' might be an ecotype of $F$. aquilonia living in more open forests 
than the normal $F$. aquilonia type. This, however, is not confirmed at least in central Finland, because $F$. polyctena (including both morphs) and $F$. aquilonia seem to use the same nesting-habitat type (based on large data on nesting-habitat characteristics; Sorvari et al. in prep.).

Recent advances in molecular methods will give new information on the identification problems in ants (e.g., Chapuisat 1996, Goropashnaya et al. 2004). Molecular methods may be needed to find out the taxonomic status of the two morphs; do they represent genetically different taxa or is the hairier morph a result of hybridisation.

In conclusion, there exist two distinct and distinguishable morphs in F. polyctena, separable by summing the number of hairs of the body parts examined. However, molecular methods are needed to answer the question why those two morphs exist. I suggest that there may be slight interbreeding between $F$. polyctena and $F$. aquilonia or some other of its hairier relatives, resulting in hairier workers in some nests of $F$. polyctena or less-hairy workers in some nests of F. aquilonia.

Acknowledgements. I thank W. Czechowski for his help in collecting samples in Hanko peninsula and T. Eeva and $\mathrm{K}$. Karhu for some of the Finnish $F$. aquilonia samples used as reference group. I also thank R. Penttinen for help with the SEM, and H. Hakkarainen, K. Vepsäläinen, R. C. Ydenberg and an anonymous referee for comments on the manuscript. The study was financially supported by the Entomological Society of Finland.

\section{References}

Adlung, K. G. 1966: A critical evaluation of the European Research on the use of Red Wood Ants (Formica rufa group) for the protection of forest against harmful insects. - Z. Angew. Entomol. 57: 167-189.

Chapuisat, M. 1996: Characterization of microsatellite loci in Formica lugubris B and their variability in other ant species. - Mol. Ecol. 5: 599-601.

Collingwood, C. A. 1979: The Formicidae (Hymenoptera) of Fennoscandia and Denmark. - Fauna Entomol. Scand. 8: 1-174.

Collingwood, C. A. \& Agosti, D. 1986: Taxonomy and zoogeography of the Formica rufa species group. Supplement to the workshop "Taxonomy and Zoogeography of the Formica rufa species group" to be held at the 10th International Congress of IUSSI, Munich 1986.

Czechowski, W. \& Douwes, P. 1996: Morphometric Char- acteristics of Formica polyctena Foerst. and Formica rufa L. (Hymenoptera, Formicidae) from the Gorce Mts; Interspecific and Intraspecific Variations. Ann. Zool. 46: 125-141.

Deslippe, R. J. \& Savolainen, R. 1994: Role of food supply in structuring a population of Formica ants. - J. Anim. Ecol. 63: 756-764.

Douwes, P. 1979: Formica rufa-gruppens systematic. Entomol. Tidskr. 100: 187-191.

Goropashnaya, A. V., Fedorov, V. B. \& Pamilo, P. 2004: Recent speciation in the Formica rufa group ants (Hymenoptera, Formicidae): inference from mitochondrial DNA phylogeny. - Mol. Phylogenet. Evol. 32: 198-206.

Niemelä, J., Haila, Y., Halme, E., Pajunen, T. \& Punttila, P. 1992: Small-scale heterogeneity in the spatial distribution of carabid beetles in the southern Finnish taiga. J. Biogeogr. 19: 173-181.

Pamilo, P., Vepsäläinen, K., Rosengren, R., Varvio-Aho S.-L. \& Pisarski, B. 1979: Population genetics of Formica ants II. Genic differentiation between species. Ann. Entomol. Fennici 45: 65-76.

Punttila, P. Niemelä, P. \& Karhu, K. 2004: The impact of wood ants (Hymenoptera: Formicidae) on the structure of invertebrate community on mountain birch (Betula pubescens ssp czerepanovii). - Ann. Zool. Fennici 41: 429-446.

Rosengren, R. 1977: Foraging strategy of wood ants (Formica rufa group). I. Age polyethism and topographic traditions. - Acta Zool. Fennica 149: 1-30.

Rosengren, R. \& Pamilo, P. 1983: The evolution of polygyny and polydomy in mound-building Formica ants. - Acta Entomol. Fennica 42: 65-77.

Rosengren, R., Fortelius, W., Lindström, K. \& Luther, A. 1987: Phenology and causation of nest heating and thermoregulation in red wood ants of the Formica rufa group studied in coniferous forest habitats in southern Finland. - Ann. Zool. Fennici 24: 147-155.

Rosengren, R., Sundström, L. \& Fortelius, W. 1993: Monogyny and polygyny in Formica ants: the result of alternative dispersal tactics. - In: Keller, L. (ed.), Queen number and sociality in insects: 308-333. Oxford University Press, Oxford, UK.

Savolainen, R. \& Vepsäläinen, K. 1988: A competition hierarchy among boreal ants: Impact on resource partitioning and community structure. - Oikos 51: 135155.

Savolainen, R. \& Vepsäläinen, K. 1989: Niche differentiation of ant species within territories of the wood ant Formica polyctena. - Oikos 56: 3-16.

Savolainen, R., Vepsäläinen, K. \& Wuorenrinne, H. 1989: Ant assemblages in the taiga biome: Testing the role of territorial wood ants. - Oecologia 81: 481-486.

Seifert, B. 1991: The phenotypes of the Formica rufa complex in East Germany. - Abh. Ber. Naturkundemus. Görlitz 65: 1-27.

Seifert, B. 1992: Formica nigricans Emery, 1909 - an ecomorph of Formica pratensis Retzius, 1783 (Hymenoptera, Formicidae). — Entomol. Fennica 2: 217 226. 
Seifert, B. 1996: Ameisen: beobachten, bestimmen. Naturbuch Verlag, Augsburg.

Vepsäläinen, K. \& Pisarski, B. 1981: The Taxonomy of the Formica rufa Group: Chaos before Order. - In:
Howse, P. E. \& Clément, J.-L. (eds.), Biosystematics of Social Insects: 27-35. Academic Press, London and New York.

Appendix. The colony-mean number of erect hairs on different body parts and head-widths (mm). Standard errors $( \pm)$ are below each mean value. For the body part abbreviations, see Material and Methods. The morphs $(\mathrm{M})$ are less-hairy $(\mathrm{h})$ and more hairy $(\mathrm{H})$. Colony numbers are the same as in Table 1.

\begin{tabular}{lccrcccccccrcc}
\hline Colony & $\mathrm{Gu}$ & $\mathrm{Cl}$ & $\mathrm{Ey}$ & $\mathrm{Hb}$ & $\mathrm{Ps}$ & $\mathrm{Pn}$ & $\mathrm{Mn}$ & $\mathrm{Mp}$ & $\mathrm{Pp}$ & $\mathrm{Pe}$ & $\mathrm{Fe}$ & $\mathrm{Hw}$ & $\mathrm{M}$ \\
\hline 1 & 3.63 & 3.37 & 10.20 & 4.17 & 3.70 & 5.93 & 9.10 & 9.00 & 4.03 & 7.73 & 23.93 & 1.74 & $\mathrm{H}$ \\
\pm & 0.55 & 0.30 & 0.92 & 1.06 & 0.59 & 1.12 & 0.75 & 1.33 & 0.83 & 0.63 & 1.53 & 0.05 & \\
2 & 0.73 & 2.07 & 11.00 & 0.47 & 1.30 & 2.67 & 2.33 & 5.00 & 1.47 & 4.9 & 17.43 & 1.78 & $\mathrm{~h}$ \\
\pm & 0.17 & 0.22 & 1.03 & 0.16 & 0.29 & 0.33 & 0.45 & 0.76 & 0.47 & 0.55 & 1.52 & 0.07 & \\
3 & 5.24 & 3.31 & 6.40 & 3.38 & 4.55 & 5.69 & 4.59 & 5.60 & 5.00 & 4.17 & 21.76 & 1.72 & $\mathrm{H}$ \\
\pm & 0.80 & 0.25 & 0.85 & 0.83 & 0.45 & 1.06 & 0.57 & 0.58 & 0.83 & 0.47 & 1.30 & 0.07 & \\
4 & 7.30 & 3.97 & 6.40 & 3.33 & 5.50 & 9.87 & 5.30 & 5.10 & 7.27 & 5.07 & 24.57 & 1.58 & $\mathrm{H}$ \\
\pm & 0.56 & 0.34 & 0.78 & 0.54 & 0.67 & 1.51 & 0.64 & 0.57 & 0.89 & 0.60 & 1.31 & 0.08 & \\
5 & 5.13 & 3.67 & 6.20 & 4.00 & 5.47 & 2.57 & 4.17 & 6.70 & 4.87 & 4.50 & 24.17 & 1.70 & $\mathrm{H}$ \\
\pm & 0.60 & 0.32 & 0.92 & 0.69 & 0.67 & 0.52 & 0.43 & 0.67 & 0.69 & 0.51 & 0.75 & 0.06 & \\
6 & 4.87 & 4.57 & 5.40 & 2.63 & 6.87 & 6.50 & 5.60 & 5.30 & 7.70 & 4.20 & 18.10 & 1.36 & $\mathrm{H}$ \\
\pm & 0.43 & 0.33 & 0.72 & 0.43 & 0.52 & 1.03 & 0.52 & 0.52 & 0.84 & 0.73 & 0.98 & 0.03 & \\
7 & 2.83 & 1.73 & 4.00 & 0.50 & 6.77 & 0.77 & 1.43 & 8.00 & 2.63 & 3.07 & 18.43 & 1.54 & $\mathrm{~h}$ \\
\pm & 0.35 & 0.21 & 0.98 & 0.18 & 0.48 & 0.23 & 0.28 & 0.91 & 0.47 & 0.43 & 0.76 & 0.04 & \\
8 & 4.10 & 1.40 & 4.40 & 0.20 & 3.60 & 0.30 & 1.50 & 5.90 & 2.60 & 4.80 & 18.40 & 1.67 & $\mathrm{~h}$ \\
\pm & 0.88 & 0.43 & 0.90 & 0.20 & 0.60 & 0.21 & 0.43 & 0.55 & 0.43 & 1.07 & 0.79 & 0.05 & \\
9 & 5.30 & 5.40 & 4.70 & 0.20 & 5.20 & 8.70 & 8.50 & 7.20 & 8.10 & 6.50 & 15.80 & 1.73 & $\mathrm{H}$ \\
\pm & 0.92 & 0.40 & 0.68 & 0.13 & 0.55 & 1.40 & 1.14 & 0.98 & 1.19 & 0.86 & 2.01 & 0.04 & \\
10 & 1.10 & 3.30 & 4.30 & 0.60 & 2.30 & 1.20 & 3.40 & 4.00 & 1.30 & 2.80 & 15.50 & 1.58 & $\mathrm{~h}$ \\
\pm & 0.28 & 0.52 & 0.87 & 0.40 & 0.58 & 0.88 & 0.79 & 0.80 & 0.45 & 0.63 & 2.00 & 0.06 & \\
11 & 3.70 & 2.80 & 5.70 & 0.10 & 3.40 & 3.00 & 2.60 & 3.70 & 1.40 & 4.60 & 13.30 & 1.62 & $\mathrm{~h}$ \\
\pm & 0.98 & 0.49 & 0.83 & 0.10 & 0.72 & 1.32 & 0.88 & 0.47 & 0.65 & 0.73 & 1.83 & 0.07 & \\
12 & 2.40 & 2.40 & 4.60 & 0.20 & 3.70 & 3.50 & 5.70 & 7.40 & 5.20 & 6.50 & 9.90 & 1.58 & $\mathrm{~h}$ \\
\pm & 0.79 & 0.34 & 0.76 & 0.13 & 0.83 & 0.96 & 0.75 & 0.86 & 0.79 & 0.85 & 2.26 & 0.08 & \\
\hline
\end{tabular}

